\title{
Synchronous or Staged Carotid Endarterectomy and Coronary Artery Bypass Grafting? Propensity score matched study
}

\author{
Sebastian Hempe, ${ }^{1}$ Ajay Moza, ${ }^{1}$ Andreas Goetzenich, ${ }^{1}$ Lachmandath Tewarie, ${ }^{1}$ Christian Bleilevens, ${ }^{2}$ Rüdiger \\ Autschbach, ${ }^{1}$ Heike Schnoering, ${ }^{\text {* }}$ Rashad Zayat, ${ }^{1 *}$ \\ ${ }^{1}$ Department of Thoracic and Cardiovascular Surgery, University Hospital RWTH Aachen, Pauwelsstrasse 30, Aachen 52074, \\ Germany; ${ }^{2}$ Department of Anesthesiology, University Hospital RWTH Aachen, Pauwelsstrasse 30, Aachen 52074, Germany
}

\section{ABSTRACT}

Background: The optimal treatment strategy in patients presenting with hemodynamically significant carotid artery disease who are to undergo cardiac surgery, remains controversial. In this study, we retrospectively analyzed the outcome data of patients receiving synchronous or staged coronary artery bypass graft (CABG) surgery and carotid endarterectomy (CEA).

Methods: Between 2011 and 2016, 3173 patients underwent CABG surgery in our institution, of whom 323 received CABG and CEA either as synchronous $(\mathrm{N}=307)$ or as staged $(\mathrm{N}=16)$ procedures. Patients' characteristics, peri- and postoperative data were collected from our digital medical database. Propensity score matching was used to match each patient from the staged group to two appropriate patients (1:2 matching) from the synchronous group (synchronousmatched).

Results: The overall incidence of ischemic stroke (IS) and transitory ischemic attack (TIA) was $4.9 \%$ and $5.6 \%$, respectively. No hemorrhagic stroke was noted in both groups. Incidence of IS did not differ significantly between matched groups $(P=1.000)$. Significantly higher rates of postoperative neurological complications, such as TIA and delirium, were found in the synchronousmatched group $(P=.041$ and $P=.043$, respectively) compared with the staged group. Additionally, there were more postoperative respiratory insufficiencies in the synchronousmatched group $(P=.043)$. Thirty days mortality did not differ significantly between the matched groups.

Conclusion: In this experience combined with the data given in literature, our findings suggest a possible superiority of the staged CABG/CEA approach. Large, randomized studies are required to verify our findings and to establish applicable guidelines.

\section{INTRODUCTION}

Due to a similar pathophysiological background, it is not surprising that there are high occurrences of concurrent

Received fune 22, 2018; accepted fuly 16, 2018.

*These authors contributed equally to this work.

Correspondence: Rashad Zayat, MD, Department of Thoracic and Cardiovascular surgery, RWTH, University Hospital Aachen. Pauwelsstraße 30, D 52074 Aachen, Germany; +49-241-80 36541; fax: +49-241-80 33 36541 (e-mail:rzayat@ukaachen.de). coronary artery disease (CAD), with the need of revascularization and severe carotid artery stenosis (6\% to $14 \%$ ) [Zhang 2017; Poi 2018; Shishehbor 2013]. Even though there are many studies investigating the outcomes of different therapeutic approaches, the management of concurrent CAD and carotid artery stenosis remains indistinct [Poi 2018; Shishehbor 2013; Levy 2012; Timaran 2008]. In the literature, the following procedures are discussed particularly: On the one hand, staged carotid endarterectomy (CEA) plus coronary artery bypass graft surgery (CABG) under the same anesthesia, and on the other hand staged CEA before CABG in more than one surgical intervention and more recently staged or synchronous carotid artery stenting (CAS) plus CABG [Poi 2018; Shishehbor 2013; Levy 2012; Timaran 2008; Van der Heyden 2007; Naylor 2009]. Although the outcomes of CAS plus CABG have improved in recent years [Feldman 2017] and seem to represent a considerable alternative to CEA in selected patients [Poi 2018], CEA remains the "gold standard" procedure for carotid revascularization [Levy 2012], which is why we focused on CEA and CABG in our study.

Regarding strategies including CEA and CABG it is unclear, whether the staged or synchronous procedure should be preferred [Gopaldas 2011; Iyem 2009]. While some authors claim that the synchronous procedure seems to have a higher risk of stroke and death, but less cardiac complications [Naylor 2003], others conclude that there are neither differences concerning mortality nor neurologic complications, but that morbidity in patients receiving the staged procedure is higher [Gopaldas 2011].

In order to offer best medical treatment with the smallest amount of complications to patients suffering from both CAD and carotid artery stenosis, we retrospectively analyzed the outcomes at our institution.

\section{MATERIALS AND METHODS}

Between 2011 and 2016 data of all patients, who underwent elective or urgent CABG and CEA in our department, were retrospectively retrieved. During this period, $3173 \mathrm{CABG}$ procedures were performed, of these 323 patients had CEA in addition to $\mathrm{CABG}$, either as synchronous $\mathrm{CABG}+\mathrm{CEA}$ ( $N=307$ ), or staged (CEA followed by CABG within the same hospitalization) procedure $(\mathrm{N}=16)$. Due to the retrospective nature of our study, informed consent was waived by the ethical committee of our institution. Patients' demographics, intra- and postoperative data were retrieved. Indication for 
Table 1. Comparison of all screened patients

\begin{tabular}{|c|c|c|c|}
\hline & $\begin{array}{l}\text { Synchronous } \\
(N=307)\end{array}$ & $\begin{array}{l}\text { Staged } \\
(N=16)\end{array}$ & $P$ \\
\hline Female N (\%) & $72(23.5)$ & $4(25)$ & .547 \\
\hline Age years & $69.2 \pm 8.3$ & $67.5 \pm 9.1$ & .401 \\
\hline EuroSCORE II & $5.3 \pm 5.1$ & $6.7 \pm 5.7$ & .343 \\
\hline $\mathrm{BMI} \mathrm{Kg} / \mathrm{m}^{2}$ & $28.2 \pm 14.4$ & $28.1 \pm 5.6$ & .936 \\
\hline COPD N (\%) & $76(21.8)$ & $5(31.3)$ & .538 \\
\hline PAD N (\%) & $79(25.7)$ & $6(37.5)$ & .380 \\
\hline IDDM N (\%) & $87(28.3)$ & $7(43.8)$ & .256 \\
\hline Arterial hypertonia $\mathrm{N}(\%)$ & $229(74.6)$ & $15(93.8)$ & .131 \\
\hline Smoking N (\%) & $24(15.7)$ & $11(68.8)$ & .328 \\
\hline Prior CVA N (\%) & $49(15.7)$ & $3(18.8)$ & .491 \\
\hline Prior MI N (\%) & $111(36.1)$ & $8(50)$ & .293 \\
\hline Prior PCI N (\%) & $11(34.4)$ & $6(37.5)$ & .148 \\
\hline Kidney disease N (\%) & $51(16.1)$ & $2(12.5)$ & .899 \\
\hline Creatinine $\mathrm{mg} / \mathrm{dL}$ & $1.0 \pm 0.3$ & $1.1 \pm 0.3$ & .261 \\
\hline Prior dialysis N (\%) & $1(0.3)$ & 0 & 1.000 \\
\hline NYHA III N (\%) & $101(32.9)$ & $7(43.8)$ & .418 \\
\hline NYHA IV N (\%) & $12(3.9)$ & $1(6.3)$ & .490 \\
\hline $1-C A D N(\%)$ & $7(2.2)$ & 0 & 1.000 \\
\hline 2-CAD N (\%) & $36(11.7)$ & $2(12.5)$ & 1.000 \\
\hline 3-CAD N (\%) & $264(85.9)$ & $14(87.5)$ & 1.000 \\
\hline Re-do surgery N (\%) & $8(2.6)$ & $1(6.3)$ & .370 \\
\hline Cross-clamp time minutes & $62.7 \pm 34.3$ & $54.2 \pm 47.3$ & .493 \\
\hline CPB time minutes & $103.5 \pm 47.6$ & $108.1 \pm 66.2$ & .791 \\
\hline
\end{tabular}

CABG and CEA procedures was recorded. All postoperative complications including neurological events within the first 30 postoperative days (POD) were identified.

Diagnosis: All patients with CAD, who were referred for CABG surgery to our institution, were assessed by neurologist and cardiac surgeons for carotid bruits and symptoms.

Patients were evaluated by duplex ultrasonography through a certified neurologist. Then, the addition of CEA to the planned CABG procedure was recommended, if patients were either asymptomatic with a stenosis $>70 \%$, or symptomatic with a stenosis $>50 \%$. In patients with sub-marginal stenosis degree, an additional cranial computed tomography (CT), with angiography, for accurate classification of the carotid artery stenosis was performed.

As there is still no guideline or enough data demonstrating the superiority of one of the procedures (staged CEA then CABG or synchronous $\mathrm{CEA}+\mathrm{CABG}$ ), the decision whether staged or simultaneous procedures is performed, was taken by the surgeon. In patients with bilateral carotid artery stenosis, staged procedure was chosen, to perform CEA of the site with the severe stenosis first, followed by CABG surgery in an interval of seven to 10 days. If necessary, the second carotid
Table 1. Comparison of all screened patients (Continued)

\begin{tabular}{lccc}
\hline & $\begin{array}{c}\text { Synchronous } \\
(\mathrm{N}=307)\end{array}$ & $\begin{array}{c}\text { Staged } \\
(\mathrm{N}=16)\end{array}$ & $P$ \\
\hline Postoperative data & & & \\
Re-thoracotomy N (\%) & $24(7.8)$ & 0 & .681 \\
MI N (\%) & $5(1.6)$ & 0 & 1.000 \\
Embolic stroke N (\%) & $16(5.2)$ & 0 & 1.000 \\
Creatinine mg/dL & $1.2 \pm 0.13$ & $0.92 \pm 0.15$ & .158 \\
Hemorrhagic stroke N (\%) & 0 & 0 & \\
TIA N (\%) & $18(5.9)$ & 0 & 1.000 \\
Respiratory insufficiency N (\%) & $100(32.5)$ & $2(12.5)$ & .105 \\
Sepsis N (\%) & $29(9.4)$ & $3(18.7)$ & .651 \\
Delirium N (\%) & $72(23.5)$ & $2(12.5)$ & .545 \\
Bleeding CEA N (\%) & $13(4.2)$ & $1(6.2)$ & .516 \\
Re-surgery CEA N (\%) & $12(3.9)$ & $1(6.2)$ & .544 \\
ICU stay days & $6.9 \pm 9.1$ & $7.6 \pm 7.1$ & .856 \\
Hospital LOS days & $18.7 \pm 19.1$ & $27 \pm 15.4$ & .103 \\
30 days mortality N (\%) & $13(4.2)$ & $1(6.3)$ & .516 \\
$>30$ days mortality N (\%) & $15(4.9)$ & $1(6.3)$ & .565 \\
\hline
\end{tabular}

BMI: body-mass-index, COPD: chronic obstructive pulmonary disorder, PAD: peripheral artery disease, IDDM: insulin dependent diabetes mellitus, CVA: cerebrovascular accident, MI: myocardial infarction, $\mathrm{PCl}$ : percutaneous coronary intervention, CAD: coronary artery disease, CPB: cardiopulmonary bypass, TIA: transient ischemic attack, CEA: carotid endarterectomy, ICU: intensive care unit, LOS: length of stay

artery was then operated simultaneously. In our study, we had only one case with severe bilateral stenosis.

Definition of neurological events: Ischemic stroke or hemorrhagic stroke were defined by the presence of an acute cerebral infarction/bleeding noted on a cranial CT scan, accompanied by neurological symptoms lasting $>24$ hours. Transitory ischemic attack was noted by neurological symptoms $<24$ hours without the presence of an acute cerebral infarction on the cranial CT.

Anesthesia and surgical technique: All procedures were performed under general anesthesia with full invasive monitoring. Anesthesia was induced with Sufentanil 0.25-0.5 $\mu \mathrm{g} / \mathrm{kg}$, Propofol 1 to $1.5 \mathrm{mg} / \mathrm{kg}$, and Rocuronium $1 \mathrm{mg} /$ $\mathrm{kg}$. Muscle relaxants were repeated during the operation, if needed. Anesthesia was maintained with Propofol 2-4 mg/ $\mathrm{kg} / \mathrm{h}$ and Sufentanil $0.5-2.0 \mu \mathrm{g} / \mathrm{kg} / \mathrm{h}$.

Dissection of the carotid arteries was usually completed while the second surgeon harvested the saphen vein. Before cross-clamping of the carotid artery, 3,000IU of Heparin were given to achieve an activated clotting time (ACT) of $\geq 180 \mathrm{~s}$. For the standard CEA, longitudinal arteriotomy was made and carried beyond the plaque both proximally and distally, followed by a patch angioplasty closure. The neck wound usually has been left open and was closed at the end of CABG 
Table 2. Pre- and intraoperative characteristics of matched cohorts

\begin{tabular}{|c|c|c|c|}
\hline & $\begin{array}{c}\text { Synchronous } \\
\text { matched }(\mathrm{N}=32)\end{array}$ & $\begin{array}{l}\text { Staged } \\
(\mathrm{N}=16)\end{array}$ & $P$ \\
\hline Female N (\%) & $8(25)$ & $4(25)$ & .133 \\
\hline Age years & $71.2 \pm 2.1$ & $67.5 \pm 9.1$ & .167 \\
\hline EuroSCORE II & $7.5 \pm 1.6$ & $6.7 \pm 5.7$ & .698 \\
\hline $\mathrm{BMI} \mathrm{Kg} / \mathrm{m}^{2}$ & $25.2 \pm 1.0$ & $28.1 \pm 5.6$ & .160 \\
\hline COPD N (\%) & $9(28.1)$ & $5(31.3)$ & .133 \\
\hline PAD N (\%) & $10(31.3)$ & $6(37.5)$ & .453 \\
\hline IDDM N (\%) & $11(34.4)$ & $7(43.8)$ & .267 \\
\hline Arterial hypertonia $\mathrm{N}(\%)$ & $30(93.8)$ & $15(93.8)$ & .089 \\
\hline Smoking N (\%) & $24(75)$ & $11(68.8)$ & .328 \\
\hline Prior CVA N (\%) & $5(15.6)$ & $3(18.8)$ & .479 \\
\hline Prior MI N (\%) & $15(46.9)$ & $8(50)$ & .070 \\
\hline Prior $\mathrm{PCl}$ n (\%) & $11(34.4)$ & $6(37.5)$ & .148 \\
\hline Kidney disease N (\%) & $6(18.7)$ & $2(12.5)$ & .130 \\
\hline Creatinine $\mathrm{mg} / \mathrm{dL}$ & $0.96 \pm 0.06$ & $1.1 \pm 0.3$ & .298 \\
\hline Prior dialysis N (\%) & 0 & 0 & \\
\hline NYHA III N (\%) & $18(56.3)$ & $7(43.8)$ & .045 \\
\hline NYHA IV N (\%) & $2(6.3)$ & $1(6.3)$ & 1.000 \\
\hline 1-CAD N (\%) & $2(6.3)$ & 0 & .475 \\
\hline 2-CAD N (\%) & $9(28.2)$ & $2(12.5)$ & .182 \\
\hline $3-C A D N(\%)$ & $21(65.6)$ & $14(87.5)$ & .055 \\
\hline Re-do surgery N (\%) & $2(6.3)$ & $1(6.3)$ & 1.000 \\
\hline Cross-clamp time minutes & $66.5 \pm 11.3$ & $54.2 \pm 47.3$ & .466 \\
\hline CPB time minutes & $109.6 \pm 9.7$ & $108.1 \pm 66.2$ & .941 \\
\hline
\end{tabular}

BMI: body-mass-index, COPD: chronic obstructive pulmonary disorder, PAD: peripheral artery disease, IDDM: insulin dependent diabetes mellitus, CVA: cerebrovascular accident, MI: myocardial infarction, PCl: percutaneous coronary intervention, CAD: coronary artery disease, CPB: cardiopulmonary bypass

procedures. All patients underwent cardiac surgery through full median sternotomy. CABGs were performed on-pump and myocardial protection was ensured through antegrade crystalloid cardioplegia with mild hypothermia $\left(32^{\circ} \mathrm{C}-34^{\circ} \mathrm{C}\right)$. Prior to cardiopulmonary bypass (CPB), Heparin was given to achieve an ACTof $\geq 400 \mathrm{~s}$.

Statistical analysis: Continuous variables are expressed as the means \pm standard deviation $(\mathrm{SD})$ and categorical variables as absolute numbers and percentages. Comparisons between the groups, before matching, were performed with the twotailed Student's t-test for continuous variables and Fisher's exact test, or $\chi^{2}$ test for categorical variables. Due to the small group of patients who had staged procedures (staged group) and to reduce selection bias, we performed propensity score matching, to match all 16 patients in the staged group with the
Table 3. Postoperative data in matched cohorts

\begin{tabular}{lccc}
\hline & $\begin{array}{c}\text { Synchronous } \\
\text { matched }(\mathrm{N}=32)\end{array}$ & $\begin{array}{c}\text { Staged } \\
(\mathrm{N}=16)\end{array}$ & $P$ \\
\hline Postoperative data & & & \\
Re-thoracotomy N (\%) & $3(9.4)$ & 0 & .248 \\
MI N (\%) & $2(6.3)$ & 0 & .479 \\
Ischemic stroke N (\%) & $1(3.1)$ & 0 & 1.000 \\
Creatinine mg/dL & $1.2 \pm 0.13$ & $0.92 \pm 0.15$ & .158 \\
Hemorrhagic stroke N (\%) & 0 & 0 & \\
TIA N (\%) & $6(18.8)$ & 0 & .041 \\
Respiratory insufficiency N (\%) & $10(31.3)$ & $2(12.5)$ & .043 \\
Sepsis N (\%) & $6(18.7)$ & $3(18.7)$ & .505 \\
Delirium N (\%) & $10(31.3)$ & $2(12.5)$ & .043 \\
Bleeding CEA N (\%) & 0 & $1(6.2)$ & .479 \\
Re-surgery CEA N (\%) & 0 & $1(6.2)$ & .479 \\
ICU stay days & $6.9 \pm 1.2$ & $7.6 \pm 7.1$ & .762 \\
Hospital LOS days & $16.5 \pm 2.1$ & $27 \pm 15.4$ & .046 \\
30 days mortality N (\%) & $1(3.1)$ & $1(6.3)$ & .479 \\
$>30$ days mortality N (\%) & $1(3.1)$ & $1(6.3)$ & .479 \\
\hline
\end{tabular}

TIA: transient ischemic attack, CEA: carotid endarterectomy, ICU: intensive care unit, LOS: length of stay

appropriate patients in the synchronous group (synchronousmatched). Propensity scores were calculated for each patient using multivariate logistic regression based on the following preoperative covariates: Age, gender, BMI, European System for Cardiac Operative Risk Evaluation II (EuroSCORE II). Patients from the staged group were matched (1:2) to synchronous patients with the closest propensity score with the nearest-neighbor algorithm without replacement and with a 0.2 matching tolerance. After matching, categorical outcomes were compared with the McNemar's test and continuous outcomes were compared with the paired t-test. All statistical analyses were performed using SPSS software, version 23.0 (Chicago, IL, USA). A two-tailed $P$-value of $<.05$ was considered significant. All $P$-values were reported as three digit numbers.

\section{RESULTS}

Table 1 gives an overview of the results we found in the whole screened population. It shows that there were neither significant differences in the preoperative, nor in the postoperative data between the two groups, even before matching. The mean age was $69.2 \pm 8.3$ years in the synchronous versus $67.5 \pm 9.1$ years in the staged group $(P=.401)$. There was $23.5 \%$ female in the synchronous group versus $25 \%$ in the staged group $(P=.547)$. The average EuroSCORE II was $5.3 \pm 5.1$ versus $6.7 \pm 5.7 \%(P=.343)$, respectively. The rates of previous cerebrovascular accidents and myocardial 
infarctions in synchronous versus staged group, were $15.7 \%$ versus $18.8 \%,(P=.491)$ and $36.1 \%$ versus $50 \%(P=.293)$, respectively. Overall incidences of postoperative ischemic stroke (IS) (4.9\% with $5.2 \%$ versus $0 \%, P=1.000)$, transitory ischemic attack (TIA) $(5.6 \%$ with $5.9 \%$ versus $0 \%, P=$ $1.000)$, delirium $(22.9 \%$ with $23.5 \%$ versus $12.5 \%, P=.545)$ and myocardial infarction (MI) $(1.5 \%$ with $1.6 \%$ versus $0 \%$, $P=1.000)$, in synchronous group versus staged group, respectively. The overall 30 -day mortality rate was $4.3 \%(4.2 \%$ versus $6.3 \%, P=.516)$.

Comparison between the matched cohort: As presented in Table 2, the only significant preoperative (before CABGsurgery) difference between our synchronous matched and staged groups was a higher incidence of NYHA-Level III in patients receiving the synchronous procedure $(56.3 \%$ versus $43.8 \%, P=.045)$. They particularly did not differ significantly in the number of preoperative cerebrovascular accidents (15.6\% versus $18.8 \%, P=.479)$.

Table 3 shows the analysis of postoperative complications in the matched cohort. The incidence of IS did not differ between the matched group $3.1 \%$ in synchronous matched versus $0 \%$ in staged group, $P=1.000)$. There was a higher incidence of neurological complications in patients receiving the synchronous procedure, regarding the number of patients suffering from TIA $(18.8 \%$ versus $0 \%, P=.041)$ and delirium (31.3\% versus $12.5 \%, P=.043)$. Furthermore, postoperative respiratory insufficiencies occurred far more often in the synchronousmatched group than in the staged one $31.3 \%$ versus $12.5 \%, P=.043)$.

Incidences of 30-day-mortality and of postoperative MIs did not differ significantly between the matched groups (3.1\% versus $6.3 \%, P=.479$ and $6.3 \%$ versus $0 \%, P=.479$, respectively).

As Table 1 shows the data prior to cardiac surgery, it is important to mention that three patients $(18.7 \%)$ out of the staged cohort suffered from interstage MI after CEA but before the CABG operation. In two of these three cases, CPR had to be performed. After ROSC, these patients immediately received CABG surgery. All three survived CABG surgery, but one of the reanimated patients died 22 days post-op.

\section{DISCUSSION}

Over the last decades there has been an ongoing controversy about the optimal treatment strategy for concurrent CAD and carotid artery stenosis [Poi 2018; Borger 1999; Van der Heyden 2008]. There are studies supporting the synchronous approach [Shishehbor 2013; Gopaldas 2011], while others indicate that the staged one can be performed safely [Nabagiez 2014; Antunes 2002]. Again, others say that there is no difference, when both strategies are compared [Iyem 2009; Naylor 2003]. In a recent review, Poi et al [Poi 2018] propose that the synchronous strategy should be reserved for patients with symptomatic carotid stenosis and unstable angina, while the staged approach could be used as a possible option in symptomatic or asymptomatic patients with stable angina. Our results show, that the staged approach seems to cause less neurological or respiratory complications, but has a risk of interstage MIs, that must not be neglected. In the following, we want to discuss our results in combination with the available literature.

Staged procedure: In a retrospective study, Nabagiez et al [Nabagiez 2014] analyzed the outcomes of 90 patients receiving staged CEA plus CABG. They showed IS and TIA rate of $1 \%$ each, which is comparable to our results. Contrarian to our findings, they detected an interstage MI rate of only $1 \%$ (subendocardial infarction, without related death and only a slightly prolonged hospital LOS with 8 days versus $7.5 \pm 3.5$ days) as opposed to $18.7 \%$, (with one related death within 30 days and a prolonged hospital stay of $37.5 \pm 17.7$ days versus $24.9 \pm 15.0$ days) in our study. This probably leads back to their shorter interstage time $(1.8 \pm 5.6$ days versus $8.3 \pm 7.9$ days, in our study). While the interstage time in our study cohort often exceeded 7 days, $89 \%$ of the patients in the study of Nabagiez et al [Nabagiez 2014] received the CABG surgery within 24 hours after CEA, suggesting that a short interstage time correlates with a lower rate of interstage MIs.

Other studies revealed an interstage MI rate from $2.5 \%$ up to $24 \%$, with mean interstage periods from 6.87 to 32.4 [Shishehbor 2013; Antunes 2002; Santos 2012]. In the literature, the perioperative mortality-rates for the staged procedure range from $1.3 \%$ to $7 \%$ [Shishehbor 2013; Naylor 2003; Borger 1999; Antunes 2002; Birchley 2010]. Even though our staged cohort is quite small, our results are within these ranges, which is why the data seems to be representative for patients receiving the staged approach.

Synchronous procedure: According to Dick et al [Dick 2011], postoperative strokes in patients receiving the synchronous procedure occur with an average rate of $3.6 \%$, which is close to the $3.1 \%$ stroke rate we found in the synchronousmatched group. Contrary to this, our whole population of patients receiving the synchronous approach showed IS rate of $5.2 \%$, which is comparable to the one reported by Jones et al [Jones 2012], who found IS rate of $5.5 \%$ in a cohort of 109 patients. The perioperative mortality rate in our matched population was at $3.1 \%$ and in the whole synchronous population it was at $4.2 \%$. Those values are comparable to the ones reported by different authors [Levy 2012; Iyem 2009; Chiti 2010; Prasad 2010; Udesh 2018]. Postoperative myocardial infarction rate is described as $0.5 \%$ to $3.6 \%$ [Shishehbor 2013; Naylor 2003; Chiti 2010]. Looking at our results we see that the MI rate in the synchronousmatched cohort $(6.3 \%)$ was higher than those reported before, but in the screened synchronous population it was at $1.6 \%$, which matches the values reported in literature. Respiratory complications, such as pneumonia, occurred in $31.3 \%$ of our matched and in $32.5 \%$ of the screened synchronous patients. Gopaldas et al [Gopaldas 2011] found a rate of respiratory complications of $19.1 \%$ within a cohort of 16639 patients. This difference might be due to differences within the cohorts or treatment strategies. All in all, it seems that the synchronous group of our matched cohort is representative for patients undergoing synchronous CEA+CABG surgery.

Comparison between the two approaches: Like in the study of Gopaldas et al [Gopaldas 2011], we did not find a significant difference in mortality between the synchronousmatched and 
the staged group $(4.2 \%$ versus $4.5 \%, P=.286$ in their study and $3.1 \%$ versus $6.3 \%, P=.479$ in our study). Contrary to their findings, with no difference in neurologic complications (3.9\% versus $3.5 \%, P=.182$ ), in our study there was a significantly higher rate of neurological complications in the synchronousmatched group. This originates from a significantly higher rate of TIAs and delirium $(18.8 \%$ versus $0 \%, P=.041$ and $31.3 \%$ versus $12.5 \%, P=.043$, respectively), while the ischemic and hemorrhagic stroke rates did not differ between the two groups $(3.1 \%$ versus $0 \%, P=1.000$ and $0 \%$ versus $0 \%$, respectively).In the same study by Gopaldas et al, they identified a significantly higher rate of respiratory complications in the staged group ( $19.1 \%$ versus $20.7 \%, P=.010)$, which is contrary to our data, indicating a significantly higher rate of respiratory insufficiencies in the synchronousmatched group ( $31.3 \%$ versus $12.5 \%, P=.043)$. Shishehbor et al [Shishehbor 2013] drew the conclusion, that staged CEA+CABG has worse outcomes than the synchronous strategy, but mostly because of the high rate of interstage events, consisting mostly of a high interstage MI-rate of $24 \%$ in a cohort with an interstage period of median 14 days. This is even higher than the $18.7 \%$ interstage MI rate in our study. Furthermore, they found an interstage death rate of $7 \%$ (in our study, there was none). Unfortunately, they do not mention if these deaths are caused by myocardial infarctions or other reasons. Concerning the postoperative (after CABG surgery in the staged group) development in the study by Shishebor et al [Shishehbor 2013], the outcomes of the two groups did not differ significantly anymore. Consequently, the most important reason for the inferiority of the staged group in the study by Shishehbor et al is the high incidence of interstage events, especially interstage MIs. Following this thought, the inferiority of the staged group might be equalized by reducing the interstage MI rate. This could possibly be achieved by reducing the interstage time to less than 24 hours, as mentioned by Nabagiez et al [Nabagiez 2014]. However, all patients analyzed by Nabagiez et al [Nabagiez 2014] received off-pump CABG procedures, which are mostly carried out with lower Heparin doses than on-pump procedures [Chakravarthy 2017], which were used in our patients. Due to this higher dose of Heparin, a higher risk of bleeding at the CEA wound has to be taken in account, especially during the first day after CEA surgery [Self 1999] (Kakisis et al [Kakisis 2016] even showed, that the non-antagonization of the Heparin given during CEA-surgery leads to a higher risk of postoperative bleeding.). In a study by Self et al [Self 1999], they showed the highest incidence of bleeding at the CEA wound during the first day ( $6 \mathrm{~h} 41 \mathrm{~min} \pm 331 \mathrm{~min}$ ) but overall, bleedings occurred up to three days post-op. For this reason, the optimal interstage time should be evaluated in further studies, to get a minimum of both, bleedings at the CEA wound and interstage MIs.

Like Gopaldas et al [Gopaldas 2011], we identified a significantly longer duration of in-hospital stay in our staged cohort $(P=.046)$. This is probably caused by the time period between the CEA and CABG surgery. This fact must not be neglected because of two reasons. Firstly, a shorter hospitalstay is important for patients' well-being and secondly, the economic point of view has to be seen. In the same study by
Gopaldas et al [Gopaldas 2011], they identified a higher cost of $\$ 23,328$ for the staged procedure. Even though, the higher cost is due to different factors, it might be at least partly reduced by shortening the length of the interstage period.

We think that the optimal treatment of concurrent CAD and carotid artery stenosis still remains unclear. On one hand, there seems to be lower rates of neurological and respiratory complications in patients undergoing the staged surgery. On the other hand, there is still the risk of interstage MIs, which occurred in $18.7 \%$ of patients in our staged cohort. If we look at the study of Nabagiez et al [Nabagiez 2014] again, it might be concluded that shorter interstage periods, or/and a strict patient selection as mentioned by Poi et al [Poi 2018], could be used, in order to reduce interstage myocardial infarctions. Assuming a lower rate of interstage MIs, our findings may indicate a possible superiority of the staged approach over the synchronous procedure, due to less neurological complications.

\section{LIMITATIONS}

Due to the fact that our study was performed retrospectively, there are a few possible sources of biases. First, no standardization between the cohorts has been performed, and second, there might be a selection bias, for we do not know the surgeon's reasons for performing a staged or synchronous surgery. Even though we tried to minimize differences between the cohorts by performing propensity matching, these sources of bias cannot be controlled. If it comes to our sample size it has to be said that even though, our cohorts seem to be representative, it is questionable whether the small number of cases, in a retrospective, single-center study is sufficient to get valid and representative results.

\section{CONCLUSION}

The results of our study, combined with the information given in literature suggest a possible superiority of the staged CEA/CABG approach over the synchronous procedure. Nevertheless, large randomized studies are necessary to verify our findings and establish appropriate guidelines. Since there are many studies which conclude that carotid artery stenting followed by CABG surgery (either as staged, or synchronous procedure) seems to be a possible alternative to procedures consisting of $\mathrm{CEA}+\mathrm{CABG}$, the new randomized studies should include these options.

\section{REFERENCES}

Antunes PE, Anacleto G, de Oliveira JM, Eugenio L, Antunes MJ. 2002. Staged carotid and coronary surgery for concomitant carotid and coronary artery disease. Eur J Cardiothorac Surg. 21(2):181-186.

Birchley D, Villaquiran J, Akowuah E, Lewis T, Ashley S. 2010. Staged carotid endarterectomy under local anaesthetic in patients requiring cardiac surgery. Ann R Coll Surg Engl. 92(5):373-378.

Borger MA, Fremes SE, Weisel RD, et al. 1999. Coronary bypass and carotid endarterectomy: does a combined approach increase risk? A metaanalysis. Ann Thorac Surg. 68(1):14-20; discussion 21. 
Chakravarthy M, Prabhakumar D, Thimmannagowda P, et al. 2017. Comparison of two doses of heparin on outcome in off-pump coronary artery bypass surgery patients: A prospective randomized control study. Ann Card Anaesth. 20(1):8-13.

Chiti E, Troisi N, Marek J, et al. 2010. Combined carotid and cardiac surgery: improving the results. Ann Vasc Surg. 24(6):794-800.

Dick AM, Brothers T, Robison JG, et al. 2011. Combined carotid endarterectomy and coronary artery bypass grafting versus coronary artery bypass grafting alone: a retrospective review of outcomes at our institution. Vasc Endovascular Surg. 45(2):130-134.

Feldman DN, Swaminathan RV, Geleris JD, et al. 2017. Comparison of Trends and In-Hospital Outcomes of Concurrent Carotid Artery Revascularization and Coronary Artery Bypass Graft Surgery: The United States Experience 2004 to 2012. JACC Cardiovasc Interv. 10(3):286-298.

Gopaldas RR, Chu D, Dao TK, et al. 2011. Staged versus synchronous carotid endarterectomy and coronary artery bypass grafting: analysis of 10-year nationwide outcomes. Ann Thorac Surg. 91(5):1323-1329; discussion 1329.

Iyem H, Buket S. 2009. Early results of combined and staged coronary bypass and carotid endarterectomy in advanced age patients in single centre. Open Cardiovasc Med J. 3:8-14.

Jones DW, Stone DH, Conrad MF, et al. 2012. Regional use of combined carotid endarterectomy/coronary artery bypass graft and the effect of patient risk. J Vasc Surg. 56(3):668-676.

Kakisis JD, Antonopoulos CN, Moulakakis KG, et al. 2016. Protamine Reduces Bleeding Complications without Increasing the Risk of Stroke after Carotid Endarterectomy: A Meta-analysis. Eur J Vasc Endovasc Surg. 52(3):296-307.

Levy E, Yakubovitch D, Rudis E, et al. 2012. The role of combined carotid endarterectomy and coronary artery bypass grafting in the era of carotid stenting in view of long-term results. Interact Cardiovasc Thorac Surg. 15(6):984-988.

Nabagiez JP, Bowman KC, Shariff MA, et al. 2014. Twenty-four hour staged carotid endarterectomy followed by off-pump coronary bypass grafting for patients with concomitant carotid and coronary disease. Ann Thorac Surg. 98(5):1613-1618.

Naylor AR, Mehta Z, Rothwell PM. 2009. A systematic review and metaanalysis of 30-day outcomes following staged carotid artery stenting and coronary bypass. Eur J Vasc Endovasc Surg. 37(4):379-387.

Naylor AR, Cuffe RL, Rothwell PM, Bell PR. 2003. A systematic review of outcomes following staged and synchronous carotid endarterectomy and coronary artery bypass. Eur J Vasc Endovasc Surg. 25(5):380-389.

Poi MJ, Echeverria A, Lin PH. 2018. Contemporary Management of Patients with Concomitant Coronary and Carotid Artery Disease. World J Surg. 42(1):272-282.

Prasad SM, Li S, Rankin JS, et al. 2010. Current outcomes of simultaneous carotid endarterectomy and coronary artery bypass graft surgery in North America. World J Surg. 34(10):2292-2298.

Santos A, Washington C, Rahbar R, Benckart D, Muluk S. 2012. Results of staged carotid endarterectomy and coronary artery bypass graft in patients with severe carotid and coronary disease. Ann Vasc Surg. 26(1):102-106.

Self DD, Bryson GL, Sullivan PJ. 1999. Risk factors for post-carotid endarterectomy hematoma formation. Can J Anaesth. 46(7):635-640.

Shishehbor MH, Venkatachalam S, Sun Z, et al. 2013. A direct comparison of early and late outcomes with three approaches to carotid revascularization and open heart surgery. J Am Coll Cardiol. 62(21):1948-1956.

Timaran CH, Rosero EB, Smith ST, et al. 2008. Trends and outcomes of concurrent carotid revascularization and coronary bypass. J Vasc Surg. 48(2):355-360; discussion 360-351.

Udesh R, Cheng H, Mehta A, Thirumala PD. 2018. Perioperative strokes following combined coronary artery bypass grafting and carotid endarterectomy: A nationwide perspective. Neurol India. 66(1):57-64.

Van der Heyden J, Lans HW, van Werkum JW, et al. 2008. Will carotid angioplasty become the preferred alternative to staged or synchronous carotid endarterectomy in patients undergoing cardiac surgery? Eur J Vasc Endovasc Surg. 36(4):379-384.

Van der Heyden J, Suttorp MJ, Bal ET, et al. 2007. Staged carotid angioplasty and stenting followed by cardiac surgery in patients with severe asymptomatic carotid artery stenosis: early and long-term results. Circulation. 116(18):2036-2042.

Zhang J, Xu RW, Fan X, Ye Z, Liu P. 2017. A Systematic Review of Early Results Following Synchronous or Staged Carotid Artery Stenting and Coronary Artery Bypass Grafting. Thorac Cardiovasc Surg. 65(4):302-310. 